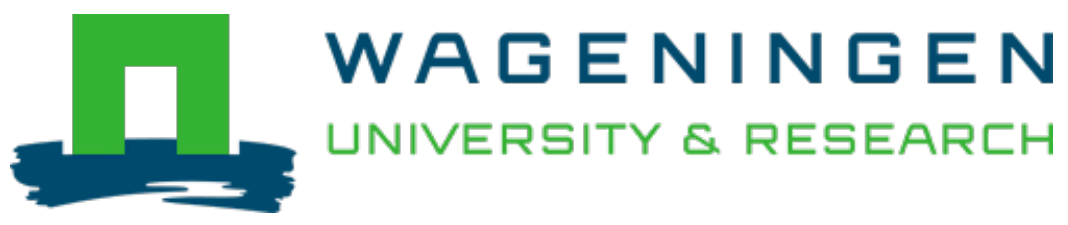

\title{
Degradation and fermentation of fructo-oligosaccharides by oral streptococci.
}

\author{
Journal of Applied Bacteriology
}

Hartemink, R.; Quataert, M.C.J.; Laere, K.M.J.; Nout, M.J.R.; Rombouts, F.M.

https://doi.org/10.1111/j.1365-2672.1995.tb03176.x

This publication is made publicly available in the institutional repository of Wageningen University and Research, under the terms of article $25 \mathrm{fa}$ of the Dutch Copyright Act, also known as the Amendment Taverne. This has been done with explicit consent by the author.

Article 25 fa states that the author of a short scientific work funded either wholly or partially by Dutch public funds is entitled to make that work publicly available for no consideration following a reasonable period of time after the work was first published, provided that clear reference is made to the source of the first publication of the work.

This publication is distributed under The Association of Universities in the Netherlands (VSNU) 'Article $25 \mathrm{fa}$ implementation' project. In this project research outputs of researchers employed by Dutch Universities that comply with the legal requirements of Article $25 \mathrm{fa}$ of the Dutch Copyright Act are distributed online and free of cost or other barriers in institutional repositories. Research outputs are distributed six months after their first online publication in the original published version and with proper attribution to the source of the original publication.

You are permitted to download and use the publication for personal purposes. All rights remain with the author(s) and / or copyright owner(s) of this work. Any use of the publication or parts of it other than authorised under article $25 \mathrm{fa}$ of the Dutch Copyright act is prohibited. Wageningen University \& Research and the author(s) of this publication shall not be held responsible or liable for any damages resulting from your (re)use of this publication.

For questions regarding the public availability of this publication please contact openscience.library@wur.nl 


\title{
Degradation and fermentation of fructo-oligosaccharides by oral streptococci
}

\author{
R. Hartemink, M.C.J. Quataert, K.M.J. van Laere, M.J.R. Nout and F.M. Rombouts \\ Department of Food Science, Wageningen Agricultural University, Wageningen, The Netherlands
}

5301/04/95: received 3 April 1995, revised and accepted 30 May 1995

R. HARTEMINK, M.C.J. QUATAERT, K.M.J. VAN LAERE, M.J.R. NOUT AND F.M. ROMBOUTS. 1995. Fructo-oligosaccharides (FOS) are claimed to have a positive effect on the intestinal flora. They are being used in functional foods in Japan and Europe. This group have tested the degradation of two commercial FOS preparations by oral streptococci in order to predict the cariogenicity of these products. Both preparations could be fermented to some extent by the species of oral streptococci tested.

The enzymes necessary for the degradation of FOS were inducible. Each strain showed a specific degradation pattern. All strains, particularly Streptococcus mutans rapidly produced acid, mainly lactic acid. Streptococcus mitis also produced high concentrations of acetic acid. Plaque formation by Strep. mutans was similar to the sucrose control. It is concluded that FOS are cariogenic to a similar extent as sucrose.

\section{INTRODUCTION}

Fructo-oligosaccharides (FOS) are a group of oligosaccharides, consisting of several $\beta(1-2)$ - or $\beta(1-6)$-linked fructose residues (Fm series), which may be linked to a glucose residue (GFn series). Two FOS mixtures are available commercially, 'Profeed' and 'Raftilose'. Profeed is produced enzymatically from sucrose using a fungal fructosyltransferase. The final product consists of a mixture of linear and branched oligosaccharides (Fig. 1) of the GFn-series. The product has been marketed as 'Neosugar', 'Meioligo', 'Actilight' or 'Nutraflora' (Hidaka et al. 1990).

Raftilose is produced enzymatically from inulin using an endo-inulinase. The final product consists of a mixture of linear oligosaccharides from both the GFn series and the Fm series. This product has also been referred to as 'Oligofructose' (Roberfroid et al. 1993).

FOS are not degraded by the human digestive enzymes and thus reach the colon unaltered (Hidaka et al. 1990). It has been shown for both commercial mixtures that a daily intake of FOS results in an increase of faecal bifidobacteria (Mitsuoka et al. 1987; Wang and Gibson 1993). An increase in faecal bifidobacteria is claimed to have a beneficial effect

Correspondence to : Ir R. Hartemink, Department of Food Science, Wageningen Agricultural University, PO Box 8129, 6700 EV Wageningen, The Netherlands. on health. FOS are therefore used as a health-promoting agent in 'functional foods' (Spiegel et al. 1994).

As FOS are widespread in nature, they are considered in food legislation as ingredients, rather than additives. In Japan this has resulted in the addition of FOS to a large range of products (Spiegel et al. 1994).

As FOS are used in many food products it is likely that some product remains in the oral cavity after consumption. It is therefore possible that FOS are degraded by the oral microflora and that, consequently, they may be cariogenic. It is well known that oral streptococci produce several fructanases, which can degrade inulin and other fructans (Hamada and Slade 1980; Walker et al. 1983; Takahasi et al. 1985; Burne et al. 1987).

Nystose (GF3), one of the components in both Raftilose and Profeed, has been claimed to be non-cariogenic (Hirasawa et al. 1984 ; Ikeda et al. 1990). However, Ziesenitz and Siebert (1987) came to the opposite conclusion. Neosugar (Profeed) has been shown to be non-cariogenic, although some acid is produced by oral streptococci (Hirasawa 1987).

Among the genera present in the oral cavity, the streptococci are considered to be the main cariogenic group of bacteria. The authors have therefore tested the degradation of FOS by members of this group, mainly Streptococcus mutans to predict the cariogenicity of this group of oligosaccharides. 

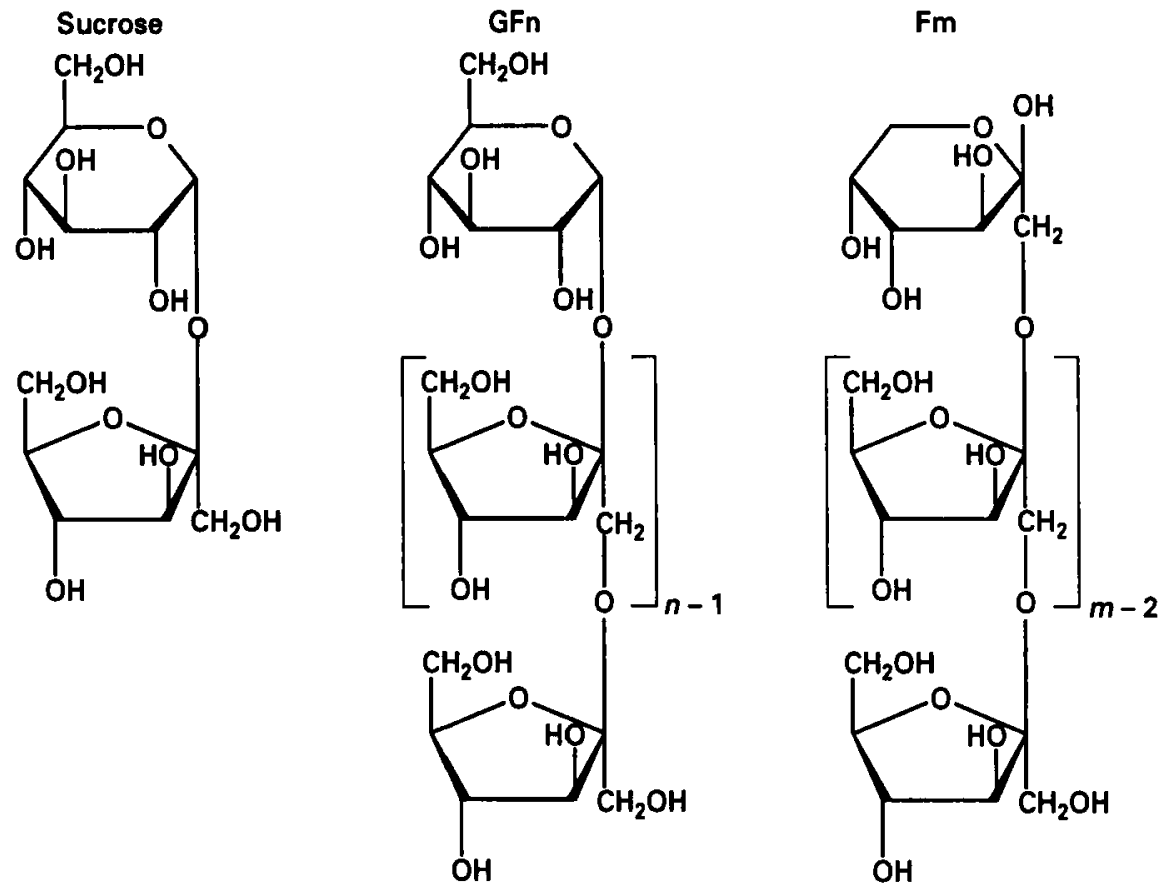

Fig. 1 Structures of fructo-cligosaccharides

\section{MATERIALS AND METHODS}

\section{Bacteria}

The following strains of oral streptococci were obtained from Dr F. H. M. Mikx, Department of Oral Microbiology, Catholic University of Nijmegen, The Netherlands : Strep. mutans 44 (Nijm. 591), Strep. oralis 45 (Nijm. 592), Strep. mitis biovar I 46 (Nijm. 593), Strep. sanguis biovar I 43 (Nijm. 594) and Strep. gordonii biovar II 42 (Nijm. 595). In addition Strep. mutans 36 (DSM 20523) was used. For the induction studies a Streptococcus sp. was isolated from saliva of a human volunteer. It was identified as Strep. salivarius, using the Rapid ID 32 Strep and the APILAB identification program (BioMérieux, Marcy-l'Etoile, France).

\section{Oligosaccharides}

Raftilose P95 was obtained from Orafti (Tienen, Belgium). Profeed P95 was obtained from Nutreco (Boxmeer, The Netherlands). Both preparations consisted of at least $95 \%$ (P95) oligosaccharides according to the manufacturers. The remaining part consists of glucose, fructose and sucrose.

\section{Screening}

FOS agar was used to screen for growth and acid formation of oral isolates. FOS agar consisted of Buffered Peptone Water (Oxoid) to which were added $\left(\mathrm{g} \mathrm{l}^{-1}\right)$ : Raftilose P95, 15 ; agar technical (Oxoid), 15 ; yeast extract (Oxoid), 5 ; and chlorophenol red (Merck), 0·05. Only Raftilose P95 was used, as most components of Profeed P95 are present in Raftilose P95 as well. Appropriate dilutions of the strains, pre-grown in Peptone-Yeast extract broth supplemented with glucose (PY-G) were applied to FOS agar plates. PY-G was prepared according to Holdeman and Moore (1977). Growth was considered positive when the colony size was over $1 \mathrm{~mm}$ diameter. Acid production was considered positive when a yellow zone was formed around the colony. Raftilose P95 contains some fermentable mono- and disaccharides. Acid formation due to fermentation of these compounds was neutralized by the buffer in the medium. Any yellow discoloration is therefore due to fermentation of oligosaccharides. The plates were incubated at $37^{\circ} \mathrm{C}$ anaerobically, using an atmosphere of $80 \%$ nitrogen, $10 \%$ hydrogen and $10 \%$ carbon dioxide (HoekL Loos, Rotterdam, The Netherlands).

\section{Induction}

Induction was studied using a Strep. salivarius strain which showed slow growth and slow acid production on FOS agar (i.e. no yellow zone within $24 \mathrm{~h}$ ). The strain was cultured in $25 \mathrm{ml}$ of PY-G. After $24 \mathrm{~h}, 100 \mu \mathrm{l}$ was inoculated into $25 \mathrm{ml}$ of PY-broth with $0.5 \%$ Raftilose P95 (PY-Raf). This strain was subsequently subcultured daily in PY-Raf for $7 \mathrm{~d}$.

Growth curves were determined by adding $25 \mu \mathrm{l}$ of a $24 \mathrm{~h}$ PY-G culture to $250 \mu \mathrm{l}$ of PY-G and PY-Raf, respectively, in a microtitre plate. Similarly $25 \mu \mathrm{l}$ of a 24 -h-old culture of Strep. salivarius subcultured seven times on PY-Raf was 
added to PY-Raf. Growth curves were determined by measuring the absorbance at $620 \mathrm{~nm}$ every $15 \mathrm{~min}$ for $11 \mathrm{~h}$ in a microtitre plate reader (E.AR 400, SLT Instruments, Groedig, Austria).

\section{Acid formation}

Acid formation was studied by culturing the following strains in HPLC-broth: Strep. mutans 36, Strep. mutans 44, Strep. oralis 45 , Strep. mitis 46, Strep. sanguis 43 and Strep. gordonii 42. HPLC broth is a medium which minimizes interference on the HPLC, it consists of $\left(\mathrm{g}^{-1}\right)$ : neutralized bacterial peptone (Difco), 5 ; yeast nitrogen base (Difco), 6; dipotassium hydrogen phosphate (anhydrous, Merck), 13; Raftilose $\mathrm{P} 95$ or Profeed $\mathrm{P} 95,10$. The $\mathrm{pH}$ was adjusted to $7 \cdot 0$ using $3 \mathrm{~mol}^{-1}$ sodium hydroxide before sterilization for 15 $\min$ at $121^{\circ} \mathrm{C}$. The strains were pre-cultured on PY-G for 16 h. All strains were grown anaerobically for $60 \mathrm{~h}$ at $37^{\circ} \mathrm{C}$. Samples were taken at $12 \mathrm{~h}$ intervals for Strep. mutans 36 and after $60 \mathrm{~h}$ for the other strains.

The samples were centrifuged for $15 \mathrm{~min}$ at $10000 \mathrm{rev}$ $\min ^{-1}$ to precipitate the cells. Lactic and acetic acids were determined using HPLC with an Aminex HPX-87H column and $0.01 \mathrm{~mol} \mathrm{l}^{-1}$ sulphuric acid as the mobile phase (Voragen et al. 1986).

\section{Rapid acidification}

For the rapid acidification experiments Strep. mutans 36 was precultured for $16 \mathrm{~h}$ in PY-G. Cells were harvested by centrifuging $100 \mathrm{ml}$ of culture and washed rwice with reduced peptone physiological salt solution (RPS). RPS consisted of $\left(\mathrm{g} \mathrm{l}^{-1}\right)$ : neutralized bacterial peptone (Difco), 1.0 ; sodium chloride (Merck), 8.5; and cysteine. $\mathrm{HCl}$ (Sigma), 0.5. The $\mathrm{pH}$ was adjusted before sterilization to 6.7 with $3 \mathrm{~mol} \mathrm{l}^{-1}$ potassium hydroxide. After the second washing the cells were resuspended in $5 \mathrm{ml}$ of RPS. For acidification tests $500 \mu \mathrm{l}$ of carbohydrate or carbohydrate/RPS mixture was added to 5 $\mathrm{ml}$ of RPS. The mixture was placed in an incubator and the $\mathrm{pH}$ was measured continuously. When the $\mathrm{pH}$ was stabilized $500 \mu \mathrm{l}$ of cell suspension was added and the $\mathrm{pH}$ was measured continuously for at least $30 \mathrm{~min}$.

\section{Fermentation patterns}

Fermentation patterns were determined by growing all strains anaerobically at $37^{\circ} \mathrm{C}$ in HPLC-broth supplemented with 20 $\mathrm{g} \mathrm{l}^{-1}$ Raftilose P95 for $60 \mathrm{~h}$. Profeed P95 was not used in this experiment, as most components of Profeed P95 are present in Raftilose P95. After $60 \mathrm{~h}$ a sample $(1 \mathrm{ml})$ was taken and centrifuged at $10000 \mathrm{rev} \mathrm{min}^{-1}$ to precipitate the cells. Residual Raftilose P95 was analysed using High Performance Anion Exchange Chromatography (HPAEC). HPAEC was performed using a BIO-LC system (Sunnyvale, CA, USA), equipped with a Dionex Carbopac PA-100 $(4 \times 250 \mathrm{~mm})$ column and a Dionex pulsed electrochemical detector in the pulsed amperometric detection method (Voragen et al. 1986). The oligosaccharides were analysed using a gradient of $0-1 \cdot 0$ mol $1^{-1}$ sodium acetate in $100 \mathrm{mmol} 1^{-1}$ sodium hydroxide.

\section{Artificial plaque formation}

Plaque formation was studied using Strep. mutans 36 . The strain was pre-cultured anaerobically at $37^{\circ} \mathrm{C}$ for $24 \mathrm{~h}$ in PY-G broth. Plaque formation was determined using the procedure described by Hirasawa et al. (1984). PY supplemented with $10 \%$ Profeed, Raftilose or sucrose was used. In a second experiment $0.1 \mathrm{~mol}^{-1}$ potassium dihydrogen phosphate was added and the $\mathrm{pH}$ adjusted to 7.0 using $3 \mathrm{~mol}$ $\mathrm{I}^{-1}$ sodium hydroxide.

\section{RESULTS}

\section{Screening}

All oral streptococci were able to grow on FOS agar. Good growth was observed within $24 \mathrm{~h}$ for all strains except Strep. sanguis 43 , which showed good growth only after $48 \mathrm{~h}$ (Table 1). Acid production was evident within $24 \mathrm{~h}$ for Strep. mutans 36 and Strep. mitis. All strains showed acid production after $3 \mathrm{~d}$, except for Strep. oralis which showed only weak acid production.

Similarly, FOS agar plates inoculated with samples of saliva from 40 healthy volunteers and four healthy piglets, all showed acid production and good growth within $48 \mathrm{~h}$.

Table 1 Growth of oral streptococci on fructo-oligosaccharide agar, containing $1 \cdot 5 \%$ Raftilose P95

Growth and acid production after

\begin{tabular}{|c|c|c|c|c|c|c|}
\hline \multirow{2}{*}{$\begin{array}{l}\text { Streptococcus } \\
\text { strain }\end{array}$} & \multicolumn{2}{|l|}{ Day 1} & \multicolumn{2}{|l|}{ Day 2} & \multicolumn{2}{|l|}{ Day 3} \\
\hline & Growth* & Acid $†$ & Growth & Acid & Growth & Acid \\
\hline gordonii 42 & ++ & + & $+t$ & ++ & $+t$ & ++ \\
\hline mitis 46 & ++ & + & ++ & ++ & ++ & ++ \\
\hline mutans 36 & ++ & + & ++ & $+t$ & ++ & ++ \\
\hline mutans 44 & ++ & + & ++ & + & ++ & ++ \\
\hline oralis 45 & +- & -- & ++ & -- & $+t$ & + \\
\hline sanguis 43 & -- & -- & $+t$ & + & ++ & + \\
\hline
\end{tabular}

*Growth: ++ , colony size over $1 \mathrm{~mm}$ diam.; + , colonies small but clearly visible; +- , colonies barely visible; -- , no visible colonies.

†Acid : ++ , yellow zone around colonies; + , orange to yellow zone;,-- no zone around colonies. 


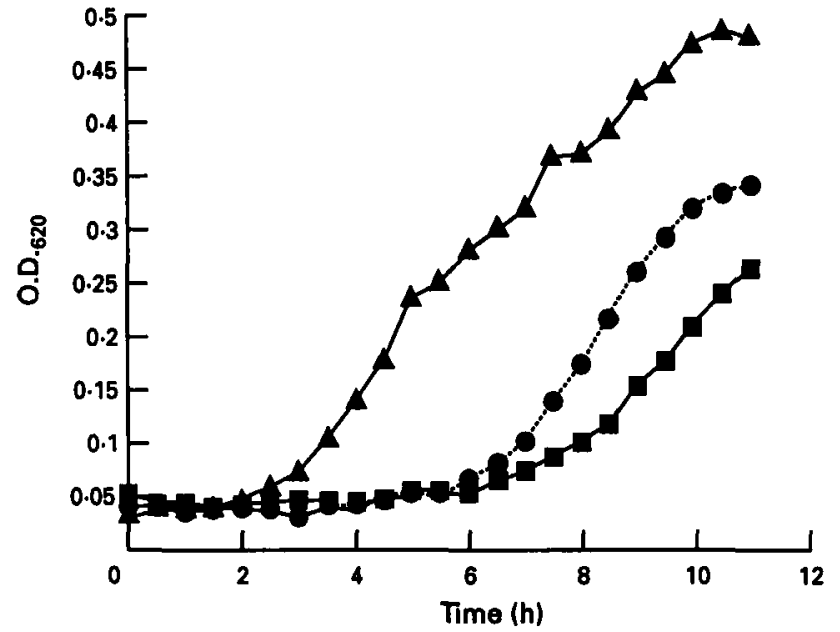

Fig. 2 Induction of growth of Streptococcus salivarius on Raftilose P95. Streptococcus salivarius was grown on PY-G. After 24 h the strain was subcultured in PY-Raf. This procedure was repeated every $24 \mathrm{~h}$. Growth of the following cultures in PY-Raf was measured in a microtitre reader with absorbance at $620 \mathrm{~nm}: \square$, pre-grown on PY-G only ; , subcultured once on PY-Raf ; $\boldsymbol{\Delta}$, subcultured four times on PY-Raf

\section{Induction}

The induction experiments with a slow-growing Strep. salivarius strain showed that the production of FOS-degrading enzymes is inducible. Figure 2 shows that the main effect is a reduced lag-phase, indicating the induction of the necessary enzymes. The growth rate was unaffected by induction.

\section{Acid formation}

All strains showed production of both lactic and acetic acids (Table 2). Lactic acid was generally present in higher concentrations than acetic acid. Most acid was produced by Strep. gordonii, Strep. mutans 36 and 44 and Strep. mitis. These strains also showed the fastest production of acid in the screening experiment. Streptococcus mitis also produced a relatively high concentration of acetic acid, indicating heterofermentative fermentation.

Streptococcus mutans 36 showed slower growth on Profeed, which resulted in lower concentrations of acid after $60 \mathrm{~h}$. Streptococcus mutans 36 produced similar amounts of acid on Raftilose as on sucrose, indicating a similar and rapid fermentation.

\section{Rapid acidification}

Acid formation was very rapid as could be concluded from this experiment. A critical $\mathrm{pH}$ for dental caries of 5.5 was reached within $15 \mathrm{~min}$ for glucose as well as both FOS preparations (Fig. 3). With a lower concentration of Raftilose
Table 2 Acid formation on 1.0\% Raftilose P95 and Profeed P95 by oral streptococci in HPLC broth

\begin{tabular}{llll}
\hline Streptococcus & $\begin{array}{l}\text { Time of } \\
\text { incubation } \\
\text { strain }\end{array}$ & $\begin{array}{l}\text { Lactic } \\
\text { acid } \\
(\mathrm{mmol}\end{array}$ & $\begin{array}{l}\text { Acetic } \\
\text { acid } \\
\left(\mathrm{mmol} \mathrm{1}^{-1}\right)\end{array}$ \\
\hline gordonii 42 & 60 & $107 \cdot 0$ & $6 \cdot 9$ \\
mitis 46 & 60 & $49 \cdot 6$ & $38 \cdot 4$ \\
mutans 36 & 12 & $1 \cdot 1$ & $9 \cdot 7$ \\
& 24 & $58 \cdot 4$ & $13 \cdot 6$ \\
& 36 & $105 \cdot 3$ & $12 \cdot 9$ \\
& 48 & $115 \cdot 4$ & $12 \cdot 4$ \\
mutans 44 & 60 & $123 \cdot 7$ & $10 \cdot 3$ \\
oralis 45 & 60 & 124 & $8 \cdot 9$ \\
sanguis 43 & 60 & $38 \cdot 2$ & $10 \cdot 3$ \\
\hline
\end{tabular}

Acid production was determined using HPLC. See Materials and Methods for details.

$\left(2.3 \mathrm{mmol}^{-1}\right)$ the critical $\mathrm{pH}$ was reached within $30 \mathrm{~min}$. No acid was produced in the absence of a fermentable carbohydrate.

\section{Oligosaccharide degradation and fermentation pattern}

The fermentation patterns of the different strains are shown in Fig. 4. It is clear that the strains degrade the FOS mixture differently. The only common factor is a complete fermentation of sucrose (GF), Streptococcus mutans 44, Strep. gordonii and Strep. mitis showed the most extensive degra-

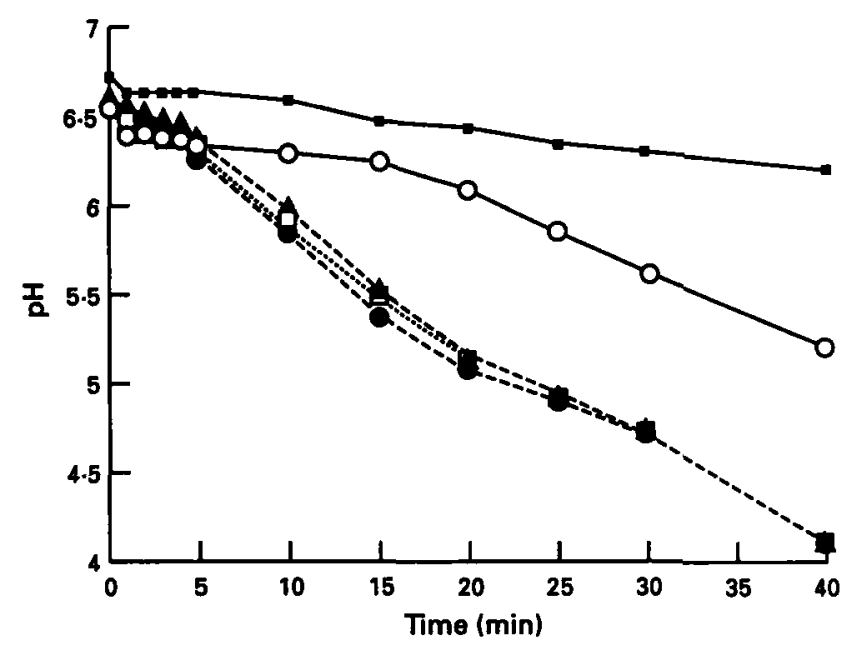

Flg. 3 Rapid acidification by Streptococcus mutans 36. Cells of Strep. mutans 36 pre-grown in PY-G for $16 \mathrm{~h}$ were washed twice with RPS and added to $500 \mu \mathrm{l}$ of RPS containing $23 \mathrm{~mol} \mathrm{I}^{-1}$ carbon sources : $\square$, no carbon source added ; $\boldsymbol{O}$, glucose; $\boldsymbol{\Delta}$, Raftilose P95; $\square$, Profeed P95; O, $2.3 \mathrm{~mol} \mathrm{l}^{-1}$ Raftilose P95 


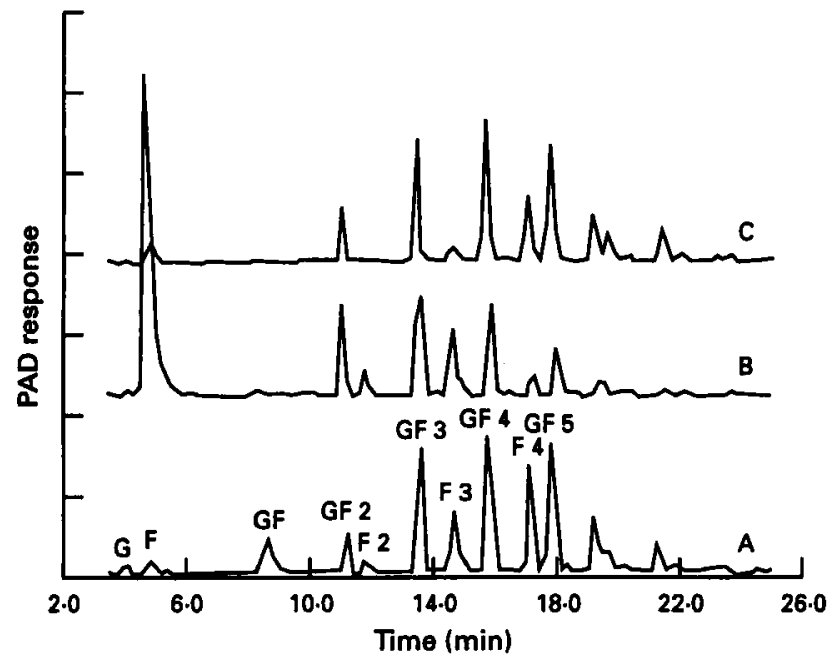

Fig. 4 Change in composition of Raftilose P95 upon fermentation by oral streptococci. Composition patterns were determined by HPLC. For experimental conditions see Materials and Methods. A, Raftilose P95 ; B, Raftilose P95 after fermentation by Streptococcus gordonii 42 ; C, Raftilose P95 after fermentation by Strep. mitis 46

dation. This is in accordance with both the screening and the acid formation experiments.

Streptococcus gordonii degraded the higher oligosaccharides, both Fm and GFn series (Table 3), thereby producing fructose, F2 and GF2. The intermediate structures F3 and GF3 seemed to be unaffected, or their degradation and formation rates are in equilibrium. Similarly, glucose levels seemed to be unaffected. This may also be due to a preference for fructose by Strep. gordonii.

Streptococcus sanguis showed only limited degradation of Raftilose. Only GF5 and F4 were degraded completely. In contrast to Strep. gordonii, no fructose accumulation was observed. On the other hand an accumulation of $F 3$ was observed, probably due to hydrolysis of a fructose residue from F4.

Streptococcus mutans 44 showed no production of GF2,
Table 4 Changes in carbohydrate pattern after incubation of $2 \%$ Raftilose P95 by Streptococcus mutans 36

\begin{tabular}{llrrr}
\hline & \multicolumn{3}{l}{ Time (h) } & \\
\cline { 2 - 5 } Component & 0 & 24 & 36 & 42 \\
\hline G (glucose) & 100 & 0 & 113 & 100 \\
F (fructose) & 100 & 0 & 1409 & 200 \\
GF (sucrose) & 100 & 0 & 6 & 0 \\
GF2 (kestose) & 100 & 19 & 29 & 0 \\
F2 & 100 & 0 & 0 & 0 \\
GF3 & 100 & 23 & 4 & 0 \\
F3 & 100 & 0 & 0 & 0 \\
GF4 & 100 & 24 & 1 & 0 \\
F4 & 100 & 0 & 0 & 0 \\
GF5 & 100 & 27 & 0 & 0 \\
\hline
\end{tabular}

Values were determined using HPLC. For experimental details see Materials and Methods. Values are relative percentages as compared to $T=0$.

Increases are due to degradation of larger oligosaccharides and incomplete fermentation.

which may be due to a better, more extensive degradation. Similarly no glucose could be detected. Large amounts of fructose and F2 were detected.

The degradation with time by Strep. mutans 36 differed from the pattern of strain 44 , in that GF3 was degraded as rapidly as the other components. Similarly no increase in F3 was observed. From the data (Table 4) it can be seen that all components were degraded rapidly, the Fm series somewhat faster. Increases in fructose and glucose were only observed after 36 h. Streptococcus oralis showed very limited degradation. Only glucose, sucrose and GF2 were degraded. Surprisingly no changes in fructose were observed.

Streptococcus mitis showed again extensive degradation. In contrast to Strep. gordonii and Strep. mutans 44 no degradation of GF3 or higher was observed. All linear fructose oligomers

Table 3 Changes in carbohydrate pattern after incubation of $2 \%$ Raftilose P95 by oral streptococci

\begin{tabular}{llllllllllll}
\hline Strain* & G & GF & GF2 & GF3 & GF4 & GF5 & F & F2 & F3 & F4 & Fm \\
\hline 42 & $/$ & --- & + & $/$ & - & -- & +++ & ++ & $/$ & -- & -- \\
43 & $/$ & --- & $/$ & $/$ & $/$ & - & - & $/$ & + & - & $/$ \\
44 & - & - & -- & $/$ & - & -- & +++ & ++ & $/$ & -- & - \\
45 & - & --- & - & $/$ & $/$ & $/$ & $/$ & $/$ & $/$ & $/$ & $/$ \\
46 & --- & --- & $/$ & - & $/$ & $/$ & + & --- & -- & - & $/$ \\
\hline
\end{tabular}

*42, Streptococcus gordonii; 43, Strep. sanguis; 44, Strep. mutans; 45, Strep. oralis; 46, Strep. mitis.

I, No visible changes; - , some degradation $(<20 \%) ;--$, degradation $(20-75 \%) ;---$, complete degradation ; + , slight increase $(<20 \%) ;++$, clear increase $(20-100 \%) ;+++$, considerable increase $(>100 \%)$.

Increases are due to degradation of larger oligosaccharides and incomplete fermentation. 
Table 5 Artificial plaque formation by Streptococcus mutans 36

\begin{tabular}{llll}
\hline $\begin{array}{l}\text { Carbon source } \\
(10 \%)\end{array}$ & $\begin{array}{l}\text { Day 1 } \\
(\mathrm{mg})\end{array}$ & $\begin{array}{l}\text { Day 2 } \\
(\mathrm{mg})\end{array}$ & $\begin{array}{l}\text { Day 3 } \\
(\mathrm{mg})\end{array}$ \\
\hline Sucrose & 11 & 14 & 16 \\
Sucrose + buffer* & 15 & 16 & 25 \\
Raftilose P95 & 12 & 10 & 18 \\
Raftilose P95+buffer & 18 & 22 & 34 \\
Profeed P95 & 8 & 5 & 13 \\
\hline
\end{tabular}

Values are average of duplicate measurements.

*Buffer was 0-1 mol l-1 $\mathrm{KH}_{2} \mathrm{PO}_{4}$, pH adjusted to 7.0.

Plaque formation was determined by growing Strep. mutans 36 on the carbon source in pre-weighed plastic tubes. After growth the tubes were emptied, dried and weighed again.

( $\mathrm{F}$ to $\mathrm{F} 4$ ) were degraded completely, as were sucrose and GF2. No accumulation of fructose could be detected. Glucose concentrations remained unaffected, similarly as in Strep. gordonii.

\section{Artificial plaque formation}

Plaque formation was determined using Strep. mutans 36 . The results (Table 5) show that Raftilose induces the formation of plaque as rapidly as does sucrose. Growth and formation of plaque on Profeed was considerably slower. However, after 3 $\mathrm{d}$ of incubation, the difference was negligible. Use of a phosphate buffer, which was added to imitate the conditions in the mouth more accurately, clearly influenced the formation of plaque. The amount of plaque formed with Raftilose as a substrate even surpassed the amount formed with sucrose.

\section{DISCUSSION}

Fermentation of fructo-oligosaccharides is very common among oral streptococci as can be concluded from these experiments. The presence of FOS-fermenting streptococci is widespread among the population, as saliva of 40 volunteers and four piglets contained strains which were able to degrade FOS (data not shown). None of the volunteers or the piglets had ever consumed commercial FOS, as at this moment no products with added FOS are on the Dutch market.

It has been shown previously (Walker et al. 1983) that oral streptococci possess fructanases. These fructanases are able to degrade levan- as well as inulin-type fructans. As the main fraction of FOS are oligomers of the inulin type, it is not surprising that all the strains tested were able to degrade FOS.

The FOS-degrading enzymes may be inducible, as was shown for a strain of Strep. salivarius. This has also been demonstrated previously for Strep. mutans using D-fructans as a substrate (Burne et al. 1987).

Various streptococci degraded FOS in a different way. Streptococcus mutans and Strep. gordonii especially showed extensive degradation of all oligomers. Streptococcus mitis, however, showed mainly degradation of the Fm series, and hardly any degradation of the GFn series. This was surprising, as in a previous study no strain of Strep. mitis seemed to produce a fructanase, when pre-grown on glucose (Walker et al. 1983). However, the latter studied only extracellular fructanases using fructan as a substrate. It is possible that fructanases are not able to degrade oligosaccharides. It is also possible that the FOS-degrading enzymes are not necessarily extracellular.

The GF3 compound, nystose, seems to be relatively stable towards degradation by most strains. Only Strep. mutans 36 rapidly degraded nystose. Streptococcus mutans 44 degraded nearly all substrates except nystose. This would also explain the results obtained by other researchers. Ikeda et al. (1990) showed that nystose was slowly degraded or fermented by five strains of Strep. mutans, among them Strep. mutans NCTC 10449, which is the same as this group's strain 36. On the other hand Ziesenitz and Siebert (1987) showed that nystose was degraded rapidly by their strain of Strep. mutans NCTC 10449 and also with human mixed dental plaque bacteria. Walker et al. (1983) reported that fructanase activities ranged from 0 to 944 units $1^{-1}$. In the same study they showed that the production of fructanase was dependent on pre-cultivation as well as medium conditions. Finally, fructanases produced by different strains showed different preferences towards fructans (Walker et al. 1983). These factors may have contributed to the observed differences towards degradation of nystose.

All species produced acid from FOS, both from Raftilose and from Profeed. Acid production on Raftilose was similar to that on sucrose, about $0 \cdot 11 \mathrm{~mol} \mathrm{l}^{-1}$. Profeed apparently is a less suitable substrate for Strep. mutans 36, as could be determined from the lower acid production and slower growth rate.

Acidification studies with Strep. mutans 36 showed that acidification is as rapid on glucose as on FOS. The critical $\mathrm{pH}$ for dental caries $(5 \cdot 5-5 \cdot 7)$ was reached within $15 \mathrm{~min}$ with $23 \mathrm{mmol}^{-1}$ FOS as substrate. This is somewhat longer than found with mixed dental plaque (Ziesenitz and Siebert 1987), which is probably due to the lower cell concentration in these experiments. Even with a reduced concentration of Raftilose $\left(2 \cdot 3 \mathrm{mmol}^{-1}\right)$ the critical $\mathrm{pH}$ was reached within half an hour.

Artificial plaque formation was similar on Raftilose and on sucrose : about $17 \mathrm{mg}$ was formed after $3 \mathrm{~d}$. Plaque formation on Profeed was somewhat less, $13 \mathrm{mg}$ after $3 \mathrm{~d}$. This data is in contrast with the results of Hirasawa et al. (1984), who could not detect any plaque after $3 \mathrm{~d}$ incubation with Neo- 
sugar (Profeed). Even if only the sucrose unit of the GFn series were utilized in plaque formation, it is to be expected that Neosugar, which consists entirely of the GFn series, would be a good substrate for plaque formation. The slower production of plaque on Profeed may again be due to the slower growth rate of Strep. mutans 36 on Profeed.

Addition of buffer increased the plaque formation considerably to about $30 \mathrm{mg}$. Surprisingly plaque formation on Raftilose surpassed plaque formation on sucrose. As sucrose is the preferred substrate for Strep. mutans glycosyltransferases (Hamada and Slade 1980), it is unlikely that Raftilose would be a better substrate. However, it has been described that oligosaccharides may act as a primer for Strep. mutans glycosyltransferase (Hamada and Slade 1980) and this may be the explanation for the increased plaque formation. As growth and acid production on Profeed was slower than on Raftilose, it is likely that the Fm series are degraded more rapidly by the streptococci. This was confirmed with the degradation experiments. Streptococcus mutans 36 degraded the Fm series faster than the GFn series, and after $60 \mathrm{~h}$ considerably more degradation of the $\mathrm{Fm}$ series could be detected with the other strains.

As all strains grow and produce acid rapidly from $\mathrm{Fm}$ and GFn oligosaccharides, it can be predicted that both substrates are cariogenic. Furthermore, artificial plaque formation occurs and this will enhance cariogenicity. Definite proof of cariogenicity, however, has to come from animal studies.

Comparison of both fructo-oligosaccharide preparations would lead to the conclusion that Raftilose is somewhat more cariogenic than Profeed, due to the slower growth rate and acid formation by the most cariogenic species, Strep. mutans, on Profeed.

\section{REFERENCES}

Burne, R.A., Schilling, K., Bowen, W.H. and Yasbin, R.E. (1987) Expression, purification, and characterization of an exo- $\beta$-D-fructosidase of Streptococcus mutans. Fournal of Bacteriology 169, 45074517.
Hamada, S. and Slade, H.D. (1980) Biology, immunology and cariogenicity of Streptococcus mutans. Microbiological Reviems 44, 331384.

Hidaka, H., Hirayama, M., Tokunaga, T. and Eida, T. (1990) The effects of undigestible fructooligosaccharides on intestinal microflora and various physiological functions on human health. In New Developments in Dietary Fiber ed. Furda, I. and Brine, C.J. pp. 105-117. New York : Plenum Press.

Hirasawa, M., Kurita, M. and Ikeda, T. (1984) Cariogenicity of fructooligosaccharides. In Proceedings of the 2nd Neosugar Research Conference. pp. 21-27. Tokyo: Meiji-Seika Publications.

Holdeman, L.V. and Moore, W.E.C. (1977) Anaerobic Laboratory Manual, 4th edn. Blacksburg: Virginia Polytechnic Institute and State University.

Ikeda, T., Kurita, T., Hidaka, H., Michalek, S.M. and Hirasawa, M. (1990) Low-cariogenicity of the tetrasaccharide nystose. General Pharmacology 21, 175-179.

Mitsuoka, T., Hidaka, H. and Eida, T. (1987) Effect of fructooligosaccharides on intestinal microflora. Die Nahrung 31, 427436.

Roberfroid, M., Gibson, G.R. and Delzenne, N. (1993) The biochemistry of oligofructose, a nondigestible fiber: an approach to calculate its caloric value. Nutrition Reviews 51, 137-146.

Spiegel, J.E., Rose, R., Karabell, P., Frankos, V.H. and Schmitt, D.F. (1994) Fructooligosaccharides as food ingredients. Food Technology 48, 85-89.

Takahashi, N.F., Mizuno, F. and Talamori, K. (1985) Purification and preliminary characterisation of exo- $\beta$-D-fructosidase in Sireptococcus salivarius KTA-19. Infection and Immunity 47, 271276.

Voragen, A.G.J., Schols, H.A., Searle-Van Leeuwen, M.F., Beldman, G. and Rombouts, F.M. (1986) Analysis of oligomeric and monomeric saccharides from enzymatically degraded polysaccharides by high-performance liquid chromatography. Fournal of Chromatography 370, 113-120.

Walker, G.J., Hare, M.D. and Morrey-Jones, J.G. (1983) Activity of fructanase in batch cultures of oral streptococci. Carbohydrate Research 113, 101-112.

Wang, X. and Gibson, G.R. (1993) Effects of the in vitro fermentation of oligofructose and inulin by bacteria growing in the human large intestine. Fournal of Applied Bacteriology 75, 373389.

Ziesenitz, S.C. and Siebert, G. (1987) In vitro assessment of nystose as a sugar substitute. Journal of Nutrition 117, 846-851. 